\title{
The contribution of the English NHS Diabetic Eye Screening Programme to reductions in diabetes-related blindness, comparisons within Europe, and future challenges
}

\author{
Peter. H. Scanlon ${ }^{1,2,3}$ (iD \\ Received: 21 January 2021 / Accepted: 5 February 2021 / Published online: 8 April 2021 \\ (c) The Author(s) 2021
}

\begin{abstract}
The aim of the English NHS Diabetic Eye Screening Programme (DESP) is to reduce the risk of sight loss amongst people with diabetes by the prompt identification and effective treatment if necessary of sight-threatening diabetic retinopathy, at the appropriate stage during the disease process, with a long-term aim of preventing blindness in people with diabetes. For the year 2009-2010, diabetic retinopathy (DR) was no longer the leading cause of blindness in the working age group. There have been further reductions in DR certifications for WHO severe vision impairment and blindness from 1,334 (5.5\% of all certifications) in 2009/2010 to 840 (3.5\% of all certifications) in 2018/2019. NHS DESP is a major contributor to this further reduction, but one must also take into account improvements in glycaemic and blood pressure control, timely laser treatment and vitrectomy surgery, improved monitoring techniques for glycaemic control, and vascular endothelial growth factor inhibitor injections for control of diabetic macular oedema. The latter have had a particular impact since first introduced in the UK in 2013.

Current plans for NHS DESP include extension of screening intervals in low-risk groups and the introduction of optical coherence tomography as a second line of screening for those with screen positive maculopathy with two dimensional markers. Future challenges include the introduction of automated analysis for grading and new camera technologies.
\end{abstract}

Keywords Screening $\cdot$ Diabetic retinopathy $\cdot$ Vision impairment $\cdot$ Blindness

\section{The English NHS Diabetic Eye Screening Programme}

The NHS Diabetic Eye Screening Programme in England commenced in 2003 and achieved high population coverage and uptake by 2008. In 2017-2018, 2.70 million people with diabetes were offered screening [1] and 2.23 million screened $(82.7 \%)$. This resulted in 8,782 urgent referrals and 54,893

This article belongs to the topical collection Eye Complications of Diabetes, managed by Giuseppe Querques.

Peter. H. Scanlon

p.scanlon@nhs.net

1 Gloucestershire Retinal Research Group, Office Above Oakley Ward, Cheltenham General Hospital, Sandford Road, Cheltenham GL53 7AN, UK

2 Nuffield Department of Clinical Neuroscience, University of Oxford, Oxford, UK

3 University of Gloucestershire, Cheltenham, UK routine referrals to ophthalmology departments. The screening method is two 45-degree field mydriatic digital photography per eye with screening and grading being undertaken by trained technicians or optometrists as previously described [2].

In 2014, Liew [3] reported that, from an analysis of blindness certifications in the year 2009-2010, for the first time in at least five decades diabetic retinopathy/maculopathy was no longer the leading cause of certifiable blindness among working age adults in England. In 2013, an eye health indicator was incorporated into the Public Health Outcomes Framework [4] in England which resulted in ongoing annual reports being produced from certificates of vision impairment (CVIs) that are gathered and collated at Moorfields Eye Hospital, which have resulted in three further publications about blindness certifications in the UK [5-7]. In England, despite an overall increase in the numbers of certifications, the numbers that have diabetic eye disease as the main cause have shown a reduction from 1334 (5.5\% of all certifications) in $2009 / 10$ to 840 (3.5\% of all certifications) in 2018/2019 (Table 1 and Fig. 1). The reduction has been principally in 


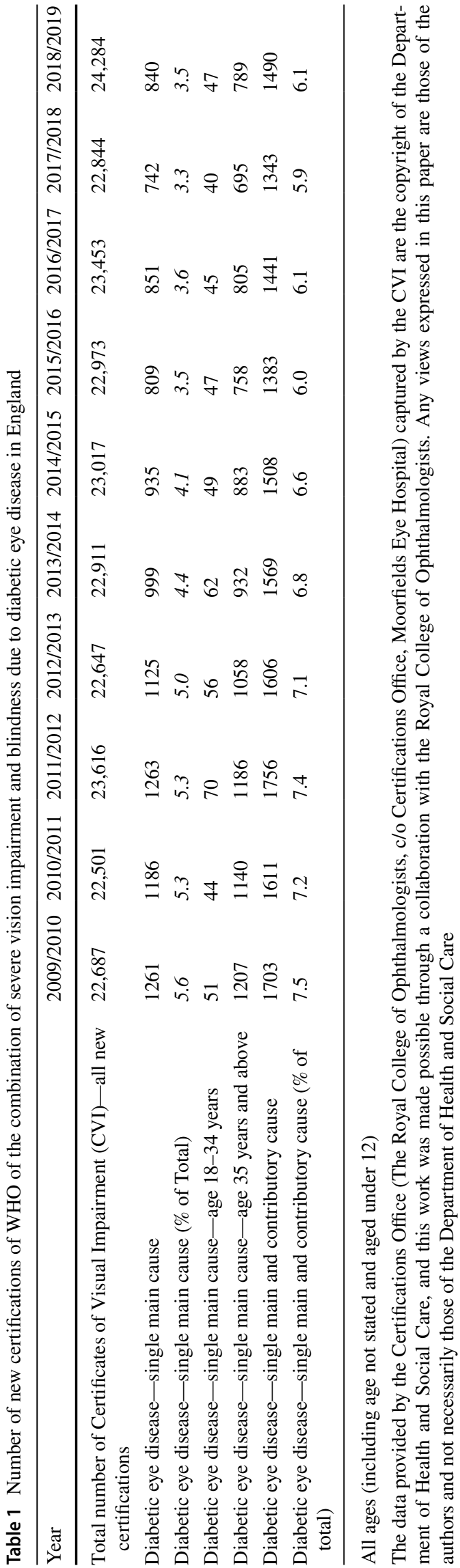

the age group 35 years and older from 1207 to 758, with an average of 51 per year in those aged 18-34 years which has shown little change over the same period.

\section{Worldwide blindness due to diabetic retinopathy}

Table 2 compares the different definitions that have been used in reporting blindness so that comparisons between studies can be more easily understood.

A 2020 publication [8] by a Vision Loss Expert Group of Collaborators reported that although diabetic retinopathy accounted for 0.86 million cases [0.59-1.23] of blindness in those aged 50 years and older in 2020, it was the smallest contributor to blindness in 2020 compared with under corrected refractive error, cataract, age-related macular degeneration, and glaucoma. However, it was the only cause of blindness that showed a global increase in age standardised prevalence between 1990 and 2020, which was of particular concern in younger, economically active age groups.

\section{Diabetes in Western Europe}

In the Diabetes Atlas 2019 report [9], the age-adjusted comparative prevalence of diabetes in Western Europe was 6.3\% expecting to rise to $7.3 \%$ in 2030.

In the UK, the National Diabetes Audit [10] from $2018-2019$ recorded $7 \%$ of the population $(3,537,385$ people) with diabetes.

A recent publication [11] describing the implementation and 15-year follow-up of a population-based screening program in Andalusia in Southern Spain, which has a population of 8.4 million, reported that the prevalence of diabetes in Andalusia is higher (15.3\%) than in the rest of Spain $(12.5 \%)$.

\section{Blindness in Western Europe}

In 2002, Kocur [12] reported that in people of working age in Europe, diabetic retinopathy was the most frequently reported causes of serious visual loss.

In 2012, Sivaprasad reported that minority ethnic communities with type 2 diabetes in the UK, in particular those of African/Afro-Caribbean's and South Asian origin, are more prone to visual impairment including sight-threatening retinopathy and maculopathy [13], compared to white Europeans.

In 2018, Bourne [14] reported that the estimated number of people registered blind in Western Europe in 2015 
Fig. 1 Percentage of new certifications of the combination of WHO severe vision impairment and blindness due to diabetic eye disease in England

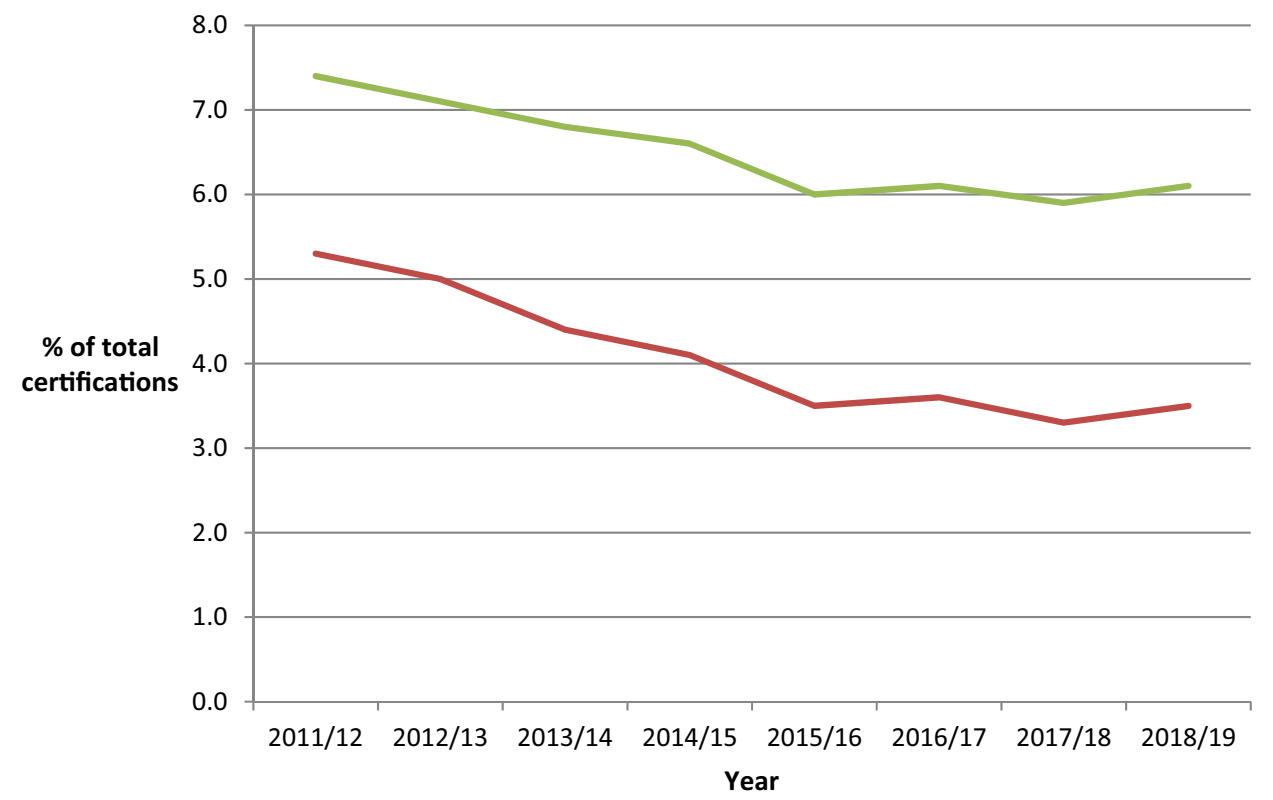

Diabetic Eye Disease Main + Contributory Cause Diabetic Eye Disease Main Cause

Table 2 Definitions of blindness and vision impairment

\begin{tabular}{|c|c|c|c|c|c|c|c|}
\hline \multirow[t]{2}{*}{ Registration } & \multirow{3}{*}{$\begin{array}{l}\text { Category } \\
\text { WHO criteria }\end{array}$} & \multicolumn{6}{|c|}{ Visual acuity in the better eye } \\
\hline & & \multicolumn{3}{|c|}{ Worse than } & \multicolumn{3}{|c|}{ Equal to or better than } \\
\hline & & $6 \mathrm{~m}$ & 20 Feet & LogMAR & $6 \mathrm{~m}$ & 20 Feet & LogMAR \\
\hline & Mild vision impairment & $6 / 12$ & $20 / 40$ & 0.3 & $6 / 18$ & $20 / 60$ & 0.48 \\
\hline & Moderate vision impairment & $6 / 18$ & $20 / 60$ & 0.48 & $6 / 60$ & $20 / 200$ & 1.0 \\
\hline $\begin{array}{l}\text { Legal blindness USA and many Western } \\
\text { European countries Sight impaired } \\
\text { Certification UK }\end{array}$ & WHO Severe vision impairment & $6 / 60$ & $20 / 200$ & 1.0 & $3 / 60$ & $20 / 400$ & 1.3 \\
\hline \multirow{5}{*}{$\begin{array}{l}\text { Seriously sight impaired/legal blindness } \\
\text { certification UK }\end{array}$} & WHO blindness & $3 / 60$ & $20 / 400$ & 1.3 & & & \\
\hline & WHO Near vision impairment & $\begin{array}{l}\text { N6 or M } \\
0.8 \text { at } \\
40 \mathrm{~cm}\end{array}$ & & & & & \\
\hline & Categorisation by Central Visual Field: & Degrees & & & & & \\
\hline & WHO Severe vision impairment & 20 & & & & & \\
\hline & WHO blindness & 10 & & & & & \\
\hline
\end{tabular}

was $1.16(0.60-1.83)$ million and that $3.30(0.47-7.60)$ $\%$ caused by DR suggesting that 38,280 people may be registered blind in Western Europe due to DR.

The 2020 publication [8] by a Vision Loss Expert Group of Collaborators report commented that there are surprisingly few data from high-income regions-only 19 studies included in the review reported cause-specific vision impairment in a high-income location, and all but three of these took place more than a decade ago.
Comparisons between studies that have been reported are made more difficult by the following:

\section{Populations studied}

a) Some studies are based on patients attending hospital clinics, and others are more population based.

b) Other studies report on the numbers per 100,000 in the general population rather than on the numbers per 100,000 with diabetes. 


\section{Incomplete reporting of data}

In the UK, retrospective reviews of WHO severe vision impairment and blindness registrations have been made in several subpopulations and at a national level like in this article. Those registers that are held locally are more likely to be complete, but registration for an individual patient is still voluntary. There are more financial benefits for an individual who is registered WHO blind (severely sight impaired UK) than one who is registered as WHO severely visually impaired (sight impaired UK) which would suggest that the former may have more complete numbers than the latter. The national figures rely on data being sent to the certifications centre at Moorfields Eye Hospital which is very complete from some areas of the country, but there will be under reporting from other areas.

\section{Mortality of those with blindness due to DR}

Only patients who were alive at follow-up may have been included in some studies even though it has been shown in the past that the mortality of those who have severe visual impairment or blindness is higher than those without [15].

\section{Patient consent}

In studies requiring patient consent, those who have lost vision may decline to participate [15].

\section{Inclusion of blindness from other causes than diabetic retinopathy}

Some studies $[16,17]$ included blindness from other causes than diabetic retinopathy in the population with diabetes. In 2003, the point prevalence [16] of legal blindness in Arhus County, Denmark, found was $0.6 \%$ for type 1 and $1.5 \%$ for type 2 diabetes patients. However, in type 1 diabetes patients, $66.2 \%$ of blind eyes were due to proliferative DR (PDR) and in type 2 diabetes, $21.9 \%$ was due to age-related macular degeneration, $18.5 \%$ diabetic maculopathy and $18 \%$ PDR.

\section{Summary of studies from Western Europe in populations with diabetes}

Tables 3 and 4 include studies that could be converted to WHO definitions of severe visual impairment and blindness due to diabetic retinopathy and to numbers per 100,000 population with diabetes. Table 3 commences in 1993-1996 with two hospital-based studies showing reductions in blindness rates in Sweden [18, 19], followed by further reports reductions in blindness from Sweden [20] and Iceland [21] that they attributed to early detection of sight-threatening diabetic retinopathy by screening programmes. Studies by Nicolucci [22] in Italy, Cormack [23] in Scotland, and Kumar [24] in Leeds, England, provide background data of blindness levels in these areas at that time. In 2001, Trautner [25] reported reductions in blindness between 1990 and 1998 in people with diabetes in the area of WurttembergHohenzollern, Germany. In 2003 Arun [26] reported registration data from Newcastle, which was an area that had pioneered screening in the UK, and reported [27] figures from the working age population in 2009. Grausland [15] reported the 25-year cumulative crude incidence of blindness in type 1 diabetes was $7.5 \%$ (men, $8.0 \%$; women, $6.8 \% ; P=0.61$ ), corresponding to a mortality-adjusted cumulative incidence of blindness of $9.5 \%$ (95\% CI, 7.1\%-12.0\%) and an overall incidence rate of blindness of 4.11 per 1000 person-years (95\% CI, 3.03-5.59 per 1000 person-years). Further reports in Tables 3 and 4 include reductions in blindness related to diabetic retinopathy in Poland [28], Cambridge UK [29], Scotland [30], Ireland [31], Wales [32], Southern Germany [33], and Gloucestershire UK [34]. A report from Hungary [35] assessed WHO severe visual impairment and blindness levels using 'Rapid Assessments of Avoidable Blindness' (RAAB) in 105 clusters.

An Italian publication in 1994 reported [36] that diabetic retinopathy was the second most common cause of blindness (13.1\%) in the province of Turin between 1967 and 1991 and the commonest cause of blindness in the age group 50-70. A further study [37] published in 2010 reported that diabetic retinopathy was the still the second most common cause of blindness (15\%) in the province of Viterbo in 2002-2003.

In Finland, a National Register of Visual Impairment (VI) was established in 1982. A 2016 publication [38] reported on 4080 patients whose primary cause for vision impairment (VI) was DR using three 10-year cohorts (1982-1990, 1991-2000, 2001-2010). A significant change had occurred over the 10-year periods particularly in those diagnosed with proliferative diabetic retinopathy, characterised by an increasing age at the time of VI notification 39, 62, and 59, decreasing severity of VI with a lower proportion blind $42 \%$, $22 \%$, and $15 \%$ and higher age at death 54,73 , and 72 years. Although the register does not collect data on type of diabetes, despite the fact that there had been an increase over this time of insulin-treated T2DM, it is believed that there has been a genuine change in characteristics of those with T1DM. This is further supported by the observation that the proportion of VI related to DR in persons of working age had decreased from $15 \%$ in 1990 to $10 \%$ in 2010 . The article also comments on an unchanged small number of blind patients with a median age of 29-31 yrs, similar to the findings in the UK of unchanged number of registrations reported in the 18-34 yrs age group, reflecting the problems 


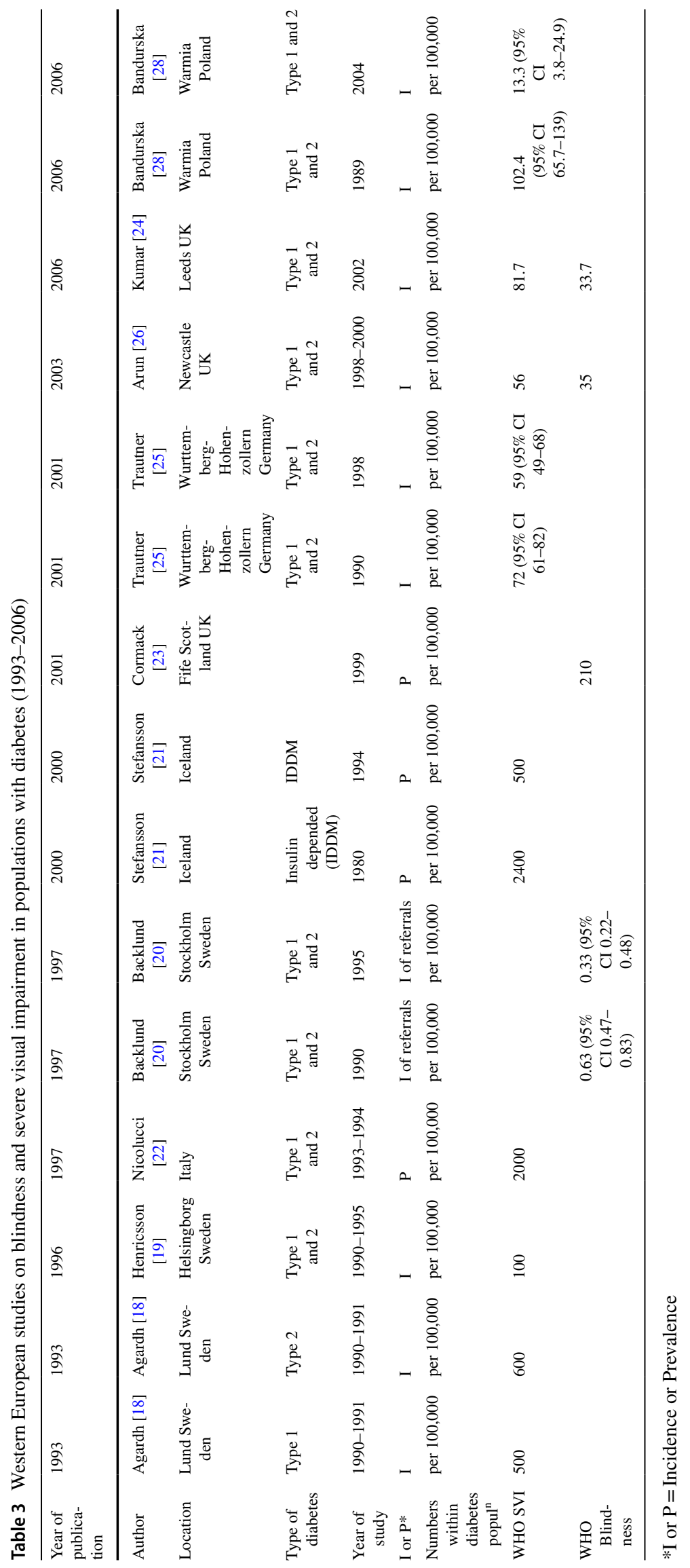




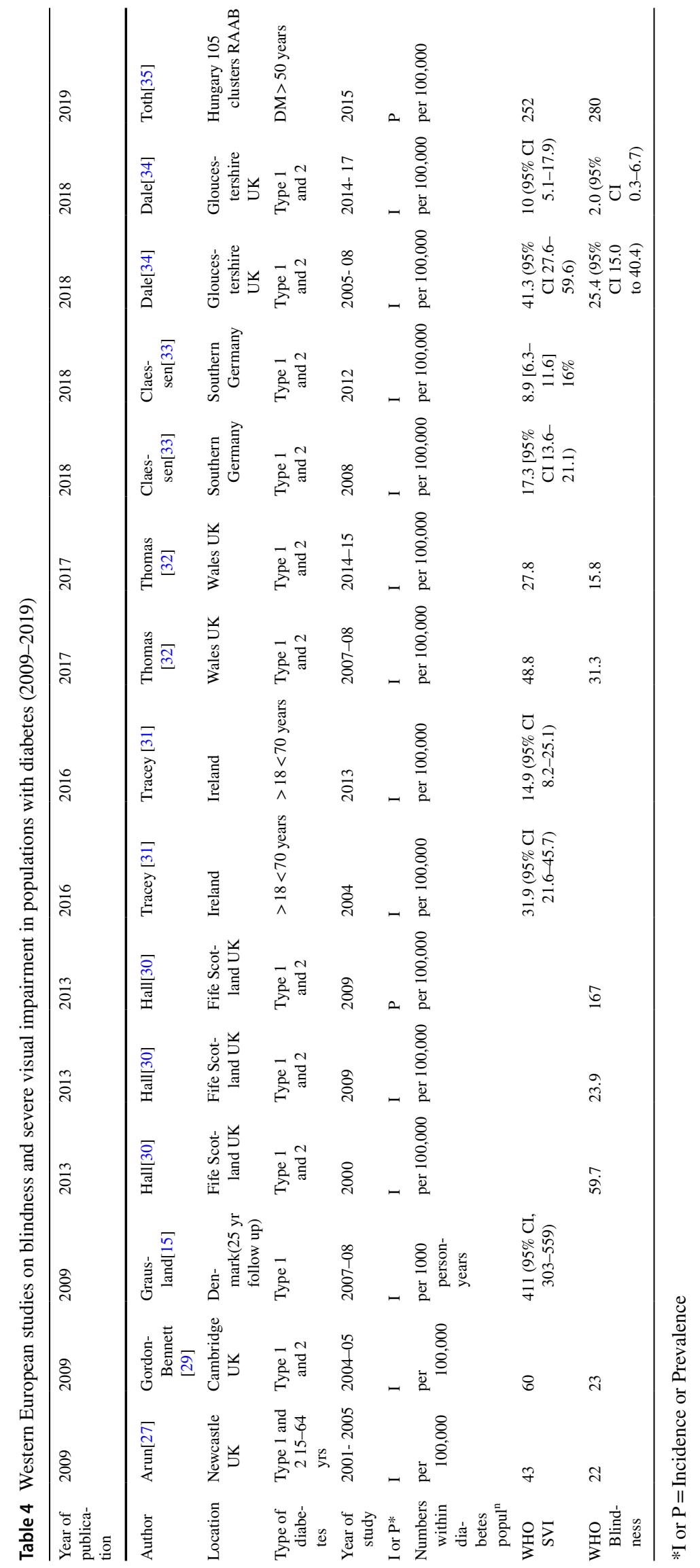


in control of diabetes in some patients with diabetes in their late teens and twenties.

\section{Contributions to reductions of blindness in Western Europe}

Landmark clinical trials and studies have shown the importance of the following factors in the development of sight-threatening diabetic retinopathy and diabetic macular oedema:

1. Glycaemic control [39-42]

2. Control of blood pressure [39, 40, 43, 44]

In addition, the following have reduced the incidence and prevalence of blindness:

3. Timely laser treatment for proliferative DR [45]

4. Timely laser treatment for clinically significant macular oedema [46]

5. Vitrectomy surgery [29]

6. Screening.

Early reports that screening and screening compliance were major contributors in preventing and/or reducing DR blindness came from Iceland [21], 47. This was reported on a larger scale when, 6 years after the introduction of the English Screening Programme, Liew [3] reported that, in the year 2009-2010, diabetic retinopathy/maculopathy was no longer the leading cause of certifiable blindness among working age adults in England. The 2019 World Report on Vision [48] produced by the World Health Organisation concluded that 'this provides compelling evidence that systematic diabetic retinopathy screening, coupled with timely treatment of sight-threatening disease, can reduce vision impairment and blindness'.

Since 2010, further contributions to reductions in blindness are:

7. Vascular endothelial growth factor (VEGF) Inhibitor injections for diabetic macular oedema

VEGF inhibitor injections for diabetic macular oedema (DME) were available in England following approval by the National Institute of Health and Care Excellence (NICE) [49, 50] in 2013-2015, and in some other parts of Europe earlier than 2013 after they gained European Regulatory approval for diabetic macular oedema in 2010[51] and 2014[52]. A modelling study [53] in Japan calculated from 570,000 DME patients was included in a model over 5 years. Increased utilization of anti-VEGF agents resulted in 6,659 fewer cases of severe visual impairment (SVI;
26-35 ETDRS letters) or blindness (0-25 ETDRS letters) compared with the current care approach.

8. Intravitreal steroid treatments for DME that were available in England following approval [54, 55] by the National Institute of Health and Care Excellence in 2013-15.

9. More recent treatments to improve glycaemic control in type 1 [56] and type 2 diabetes [57]

10. Improved methods of monitoring [58] glycaemic control.

\section{Future developments and challenges for the English NHS Diabetic Eye Screening Programme}

The current plans for the English NHS Diabetic Eye Screening Programme are.

1. Extension of screening intervals for low-risk groups based on their previous two screening results [59].

This is because we do not have easy access to other risk factor data and the most significant risk factor is what if any retinopathy was present on the most recent screening photographs [60].

2. The introduction of optical coherence tomography (OCT) in second-line digital surveillance clinics for those with screen positive diabetic maculopathy [61].

Our future challenges are:

1. The introduction of automated analysis for grading.

My own view is that we are most likely to introduce this at the DR/No DR level as they do in Scotland [62] to remove normal images from the grading queue in order to reduce the workload for graders in the English Screening Programme.

2. The assessment and introduction of new camera technologies for screening

If the new scanning confocal ophthalmoscopes are as good as is claimed [63] in the non-mydriatic format, there would be many advantages in introducing staged mydriasis into the English Screening Programme. At the present time, Scotland has to dilate $30 \%$ of their screening population [64] with higher numbers in older people with diabetes (62\% $\geq 85 \mathrm{yrs}$ and $50 \% 75-84 \mathrm{yrs}$ ).

If we could find a camera that successfully photographs the area covered by the two 45 degree fields currently used 
by the English NHS DESP, the ungradable image rate without drops was $<10 \%$, and this was shown to be cost-effective (i.e., was not prohibitively expensive), this would be very attractive to the programme. There are many factors that influence young people with diabetes in resisting attendance at screening, but removing the need for dilating eye drops may be one that could help attendance in this age group.

Acknowledgements I am grateful to Antra Zekite, Research Coordinator at Moorfields Eye Hospital NHS Foundation Trust, Catey Bunce Statistician, at the London School of Hygiene and Tropical Medicine and Mr Declan Flanagan (Vice President of the Royal College of Ophthalmologists) for their helpful comments on the data provided by the Certifications Office at Moorfields Eye Hospital.

Funding No funding was received for this work.

Data availability The data provided by the Certifications Office (The Royal College of Ophthalmologists, c/o Certifications Office, Moorfields Eye Hospital) captured by the CVI are the copyright of the Department of Health and Social Care, and this work was made possible through a collaboration with the Royal College of Ophthalmologists. Any views expressed in this paper are those of the authors and not necessarily those of the Department of Health and Social Care.

\section{Compliance with ethical standards}

Conflict of interest Peter Scanlon is Clinical Director of the English NHS Diabetic Eye Screening Programme.

Human and animal rights This article does not contain any studies with human or animal subjects performed by the any of the authors.

Open Access This article is licensed under a Creative Commons Attribution 4.0 International License, which permits use, sharing, adaptation, distribution and reproduction in any medium or format, as long as you give appropriate credit to the original author(s) and the source, provide a link to the Creative Commons licence, and indicate if changes were made. The images or other third party material in this article are included in the article's Creative Commons licence, unless indicated otherwise in a credit line to the material. If material is not included in the article's Creative Commons licence and your intended use is not permitted by statutory regulation or exceeds the permitted use, you will need to obtain permission directly from the copyright holder. To view a copy of this licence, visit http://creativecommons.org/licenses/by/4.0/.

\section{References}

1. PHE (2019) NHS screening programmes in England. 1 April 2017-31 March 2018. https://assets.publishing.service.gov. uk/government/uploads/system/uploads/attachment_data/file/ 783537/NHS_Screening_Programmes_in_England_2017_to_ 2018 final.pdf.

2. Scanlon PH (2017) The English national screening programme for diabetic retinopathy 2003-2016. ActaDiabetol 54(6):515-525. https://doi.org/10.1007/s00592-017-0974-1

3. Liew G, Michaelides M, Bunce C (2014) A comparison of the causes of blindness certifications in England and Wales in working age adults (16-64 years), 1999-2000 with 2009-2010. BMJ Open 4(2):e004015. https://doi.org/10.1136/bmjopen-2013-004015
4. Wang J, Gao X, Liu J et al (2019) Effect of intravitreal conbercept treatment on the expression of Long noncoding RNAs and mRNAs in proliferative diabetic retinopathy patients. ActaOphthalmol 97(6):e902-e912. https://doi.org/10.1111/aos.14083

5. Quartilho A, Simkiss P, Zekite A, Xing W, Wormald R, Bunce C (2016) Leading causes of certifiable visual loss in England and Wales during the year ending 31 March 2013. Eye (London, England) 30(4):602-607. https://doi.org/10.1038/eye.2015.288

6. Rahman F, Zekite A, Bunce C, Jayaram H, Flanagan D (2020) Recent trends in vision impairment certifications in England and Wales. Eye (London, England) 34(7):1271-1278. https://doi.org/ 10.1038/s41433-020-0864-6

7. Lawrenson JG, Bourmpaki E, Bunce C et al (2020) Trends in diabetic retinopathy screening attendance and associations with vision impairment attributable to diabetes in a large nationwide cohort. Diabet Med J Br DiabetAssoc. https://doi.org/10.1111/ dme. 14425

8. VLEGroup (2020) Causes of blindness and vision impairment in 2020 and trends over 30 years, and prevalence of avoidable blindness in relation to VISION 2020: the Right to Sight: an analysis for the Global Burden of Disease Study. Lancet Glob Health. https://doi.org/10.1016/S2214-109X(20)30489-7

9. Saeedi P, Petersohn I, Salpea P et al (2019) Global and regional diabetes prevalence estimates for 2019 and projections for 2030 and 2045: Results from the International Diabetes Federation Diabetes Atlas, 9(th) edition. Diabetes Res ClinPract 157:107843. https://doi.org/10.1016/j.diabres.2019.107843

10. NDA (2019) National diabetes audit 2018-19 Full Report 1, Care processes and treatment targets. https://digital.nhs.uk/dataand-information/publications/statistical/national-diabetes-audit

11 Rodriguez-Acuna R, Mayoral E, Aguilar-Diosdado M et al (2020) Andalusian program for early detection of diabetic retinopathy implementation and 15-year follow-up of a population-based screening program in Andalusia, Southern Spain. BMJ Open Diabetes Res Care. https://doi.org/10.1136/ bmjdrc-2020-001622

12. Kocur I, Resnikoff S (2002) Visual impairment and blindness in Europe and their prevention. Br J Ophthalmol 86(7):716-722

13. Sivaprasad S, Gupta B, Gulliford MC, Dodhia H, Mohamed M, Nagi D, Evans JR (2012) Ethnic variations in the prevalence of diabetic retinopathy in people with diabetes attending screening in the United Kingdom (DRIVE UK). PLoS ONE 7(3):e32182. https://doi.org/10.1371/journal.pone.0032182

14 Bourne RRA, Jonas JB, Bron AM et al (2018) Prevalence and causes of vision loss in high-income countries and in Eastern and Central Europe in 2015: magnitude temporal trends and projections. Br J Ophthalmol 102(5):575-585. https://doi.org/10.1136/ bjophthalmol-2017-311258

15. Grauslund J, Green A, Sjolie AK (2009) Blindness in a 25-year follow-up of a population-based cohort of Danish type 1 diabetic patients. Ophthalmology 116(11):2170-2174. https://doi.org/10. 1016/j.ophtha.2009.04.043

16. Jeppesen P, Bek T (2004) The occurrence and causes of registered blindness in diabetes patients in Arhus County. Denmark ActaophthalmologicaScandinavica 82(5):526-530

17. Scanlon PH, Foy C, Chen FK (2008) Visual acuity measurement and ocular co-morbidity in diabetic retinopathy screening. Br J Ophthalmol 92(6):775-778. https://doi.org/10.1136/bjo.2007. 128561

18. Agardh E, Agardh CD, Hansson-Lundblad C (1993) The five-year incidence of blindness after introducing a screening programme for early detection of treatable diabetic retinopathy. Diabetic Med J Br Diabetic Assoc 10(6):555-559

19. Henricsson M, Tyrberg M, Heijl A, Janzon L (1996) Incidence of blindness and visual impairment in diabetic patients participating 
in an ophthalmological control and screening programme. ActaOphthalmolScand 74(6):533-538

20. Backlund LB, Algvere PV, Rosenqvist U (1997) New blindness in diabetes reduced by more than one-third in Stockholm County. Diabetic Med J Br Diabetic Assoc 14(9):732-740

21. Stefansson E, Bek T, Porta M, Larsen N, Kristinsson JK, Agardh E (2000) Screening and prevention of diabetic blindness. ActaOphthalmolScand 78(4):374-385

22. Nicolucci A, Scorpiglione N, Belfiglio M et al (1997) Patterns of care an Italian diabetic population. the Italian Study Group for the Implementation of the St Vincent Declaration, SocietaItaliana di DiabetologiaAssociazione Medici Diabetologi. Diabetic Med J Br Diabetic Assoc 14(2):158-166

23. Cormack TG, Grant B, Macdonald MJ, Steel J, Campbell IW (2001) Incidence of blindness due to diabetic eye disease in Fife 1990-9. Br J Ophthalmol 85(3):354-356

24. Kumar N, Goyder E, McKibbin M (2006) The incidence of visual impairment due to diabetic retinopathy in Leeds. Eye 20(4):455-459

25. Trautner C, Haastert B, Giani G, Berger M (2001) Incidence of blindness in southern Germany between 1990 and 1998. Diabetologia 44(2):147-150

26. Arun CS, Ngugi N, Lovelock L, Taylor R (2003) Effectiveness of screening in preventing blindness due to diabetic retinopathy. Diabetic Med J Br Diabetic Assoc 20(3):186-190

27. Arun CS, Al-Bermani A, Stannard K, Taylor R (2009) Longterm impact of retinal screening on significant diabetes-related visual impairment in the working age population. Diabetic Med J Br Diabetic Assoc 26(5):489-492. https://doi.org/10.1111/j. 1464-5491.2009.02718.x

28. Bandurska-Stankiewicz E, Wiatr D (2006) Diabetic blindness significantly reduced in the Warmia and Mazury Region of Poland: Saint Vincent Declaration targets achieved. Eur J Ophthalmol 16(5):722-727

29. DVS (1990) Early vitrectomy for severe vitreous hemorrhage in diabetic retinopathy. Four-year results of a randomized trial: Diabetic Retinopathy Vitrectomy Study Report 5. Arch Ophthalmol 108(7):958-964

30. Hall HN, Chinn DJ, Sinclair A, Styles CJ (2013) Epidemiology of blindness attributable to diabetes in Scotland: change over 20 years in a defined population. Diabetic Med J Br Diabetic Assoc 30(11):1349-1354. https://doi.org/10.1111/dme.12223

31. Tracey ML, McHugh SM, Fitzgerald AP, Buckley CM, Canavan RJ, Kearney PM (2016) Trends in blindness due to diabetic retinopathy among adults aged $18-69$ years over a decade in Ireland. Diabetes Res ClinPract 121:1-8. https://doi.org/10.1016/j. diabres.2016.08.016

32. Thomas RL, Luzio SD, North RV et al (2017) Retrospective analysis of newly recorded certifications of visual impairment due to diabetic retinopathy in Wales during 2007-2015. BMJ Open. https://doi.org/10.1136/bmjopen-2016-015024

33. Claessen H, Kvitkina T, Narres M, Trautner C, Zollner I, Bertram B et al (2018) Markedly decreasing incidence of blindness in people with and without diabetes in southern Germany. Diabetes Care 41(3):478-484. https://doi.org/10.2337/dc17-2031

34. Dale A, Stratton IM, Aldington SJ, Price K, Scanlon PH (2018) Reduction in Blindness Rates Since the Introduction of Digital Photographic Screening in an English Diabetic Eye Screening Programme. Paper presented at the 28th Meeting of the European Association for the Study of Diabetes Eye Complications Study Group (EASDec), Belfast,

35 Tóth G, Szabó D, Sándor GL et al (2019) Diabetes and blindness in people with diabetes in Hungary. European J Ophthalmol 29(2):141-147. https://doi.org/10.1177/1120672118811738

36. Porta M, Tomalino MG, Santoro F et al (1995) Diabetic retinopathy as a cause of blindness in the province of Turin, north-west Italy, in 1967-1991. Diabetic Med J Br Diabetic Assoc 12(4):355-361. https://doi.org/10.1111/j.1464-5491. 1995.tb00492.x

37. Cruciani F, Abdolrahimzadeh S, Vicari A, Amore FM, Di Pillo S, Mazzeo L (2010) Causes of blind certification in an Italian Province and Comparison with other European Countries. La ClinicaTerapeutica 161(1):e11-e16

38. Laatikainen L, Ojamo M, Rudanko SL et al (2016) Improving visual prognosis of the diabetic patients during the past 30 years based on the data of the finnish register of visual impairment. ActaOphthalmol 94(3):226-231. https://doi.org/10.1111/aos.12952

39. Klein R, Moss SE, Klein BE, Davis MD, DeMets DL (1989) The Wisconsin epidemiologic study of diabetic retinopathy XI the incidence of macular edema. Ophthalmology 96(10):1501-1510

40. Klein R, Knudtson MD, Lee KE, Gangnon R, Klein BE (2009) The Wisconsin epidemiologic study of diabetic retinopathy XXIII: the twenty-five-year incidence of macular edema in persons with type 1 diabetes. Ophthalmology 116(3):497-503

41. UKPDS (1998) Intensive blood-glucose control with sulphonylureas or insulin compared with conventional treatment and risk of complications in patients with type 2 diabetes (UKPDS 33). UK Prospective Diabetes Study (UKPDS) Group. Lancet 352(9131):837-853

42. DCCT (1993) The effect of intensive treatment of diabetes on the development and progression of long-term complications in insulin-dependent diabetes mellitus. the diabetes control and complications trial research group. N Engl J Med 329(14):977-986

43. Joner G, Brinchmann-Hansen O, Torres CG, Hanssen KF (1992) A nationwide cross-sectional study of retinopathy and microalbuminuria in young Norwegian type 1 (insulin-dependent) diabetic patients. Diabetologia 35(11):1049-1054

44. UKPDS (1998) Tight blood pressure control and risk of macrovascular and microvascular complications in type 2 diabetes: UKPDS 38. UK Prospect Diabetes Study Group Bmj 317(7160):703-713

45. DRS (1978) Photocoagulation treatment of proliferative diabetic retinopathy: the second report of diabetic retinopathy study findings. Ophthalmology 85(1):82-106

46. ETDRS (1985) Photocoagulation for diabetic macular edema. early treatment diabetic retinopathy study report number 1 . early treatment diabetic retinopathy study research group. Arch Ophthalmol 103(12):1796-1806

47. Zoega GM, Gunnarsdottir T, Bjornsdottir S, Hreietharsson AB, Viggosson G, Stefansson E (2005) Screening compliance and visual outcome in diabetes. ActaOphthalmolScand 83(6):687-690

48. WHO (2020) World report on vision. https://www.who.int/publi cations-detail/world-report-on-vision. Accessed 23/04/20

49. NICE (2013) Ranibizumab for treating diabetic macular oedema (rapid review of technology appraisal guidance 237). http://publi cations.nice.org.uk/ranibizumab-for-treating-diabetic-macularoedema-rapid-review-of-technology-appraisal-guidance-ta274 Accessed 16/04/2014

50. NICE (2015) Aflibercept for treating diabetic macular oedema. Technology appraisal guidance [TA346]. https://www.nice.org. uk/guidance/ta346/chapter/1-guidance.

51. EMA (2010) European Medicines Agency. Summary of Opinion (post-authorisation) for Lucentis (ranubizumab). https:// www.ema.europa.eu/en/documents/smop/chmp-post-authorisat ion-summary-positive-opinion-lucentis_en-2.pdf. Accessed 17th January 2021

52. EMA (2014) EMA. The addition of a new indication for EYLEA (Aflibercept) in adults for the treatment of diabetic macular oedema (DME). https://www.ema.europa.eu/en/documents/varia tion-report/eylea-h-c-2392-ii-0009-epar-assessment-report-varia tion_en.pdf. Accessed 17th January 2021

53. Kitano S, Sakamoto T, Goto R, Fukushima A, Vataire AL, Hikichi Y (2019) The impact of anti-vascular endothelial growth factor 
agents on visual impairment/blindness prevention in patients with diabetic macular edema and on associated patient and caregiver burden in Japan. J Med Econ 22(3):254-265. https://doi.org/10. 1080/13696998.2018.1558867

54. NICE (2013) Fluocinolone acetonide intravitreal implant for treating chronic diabetic macular oedema after an inadequate response to prior therapy. Technology appraisal guidance [TA301].

55. NICE (2015) Dexamethasone intravitreal implant for treating diabetic macular oedema. Technology appraisal guidance [TA349]

56. Pathak V, Pathak NM, O’Neill CL, Guduric-Fuchs J, Medina RJ (2019) Therapies for type 1 diabetes: current scenario and future perspectives. Clin Med Insights Endocrinol Diabetes 12:1179551419844521. https://doi.org/10.1177/1179551419 844521

57. Chaudhury A, Duvoor C, Reddy Dendi VS et al (2017) Clinical review of antidiabetic drugs: implications for type 2 diabetes mellitus management. Front Endocrinol 8:6. https://doi.org/10.3389/ fendo.2017.00006

58 Villena Gonzales W, Mobashsher AT, Abbosh A (2019) The progress of glucose monitoring-a review of invasive to minimally and non-invasive techniques, devices and sensors. Sensors. https://doi. org/10.3390/s19040800

59. Stratton IM, Aldington SJ, Taylor DJ, Adler AI, Scanlon PH (2013) A simple risk stratification for time to development of sight-threatening diabetic retinopathy. Diabetes Care 36(3):580 585. https://doi.org/10.2337/dc12-0625

60. Scanlon PH, Aldington SJ, Leal J et al (2015) Development of a cost-effectiveness model for optimisation of the screening interval in diabetic retinopathy screening. Health Technol Assess 19(74):1-116. https://doi.org/10.3310/hta19740

61. Leal J, Luengo-Fernandez R, Stratton IM, Dale A, Ivanova K, Scanlon PH (2019) Cost-effectiveness of digital surveillance clinics with optical coherence tomography versus hospital eye service follow-up for patients with screen-positive maculopathy. Eye 33(4):640-647. https://doi.org/10.1038/s41433-018-0297-7

62. Styles CJ (2019) Introducing automated diabetic retinopathy systems: it's not just about sensitivity and specificity. Eye (London, England) 33(9):1357-1358. https://doi.org/10.1038/ s41433-019-0535-7

63. Silva PS, Cavallerano JD, Tolls D et al (2014) Potential efficiency benefits of nonmydriaticultrawide field retinal imaging in an ocular telehealth diabetic retinopathy program. Diabetes Care 37(1):50-55. https://doi.org/10.2337/dc13-1292

64. Styles C, Lee N, Black N, Ah-See K (2020) Use of dilating drops in the scottish diabetic retinopathy screening programme. Paper presented at the 30th meeting of the European Association for the Study of Diabetes Eye Complications Study Group (EASDec), Barcelona Spain Virtual Meeting

Publisher's Note Springer Nature remains neutral with regard to jurisdictional claims in published maps and institutional affiliations. 